This is a self-archived version of an original article. This version may differ from the original in pagination and typographic details.

Author(s): ${ }^{\text {Laaksonen, Ola; Peltoniemi, Mirva }}$

Title: The Essence of Dynamic Capabilities and their Measurement

Year: 2018

Version: Published version

Copyright: @ 2016 British Academy of Management and John Wiley \& Sons Ltd.

Rights: In Copyright

Rights url: http://rightsstatements.org/page/lnC/1.0/?language=en

Please cite the original version:

Laaksonen, O., \& Peltoniemi, M. (2018). The Essence of Dynamic Capabilities and their Measurement. International Journal of Management Reviews, 20(2), 184-205.

https://doi.org/10.1111/ijmr.12122 


\title{
The Essence of Dynamic Capabilities and their Measurement
}

\author{
Ola Laaksonen and Mirva Peltoniemi ${ }^{1}$ \\ Katajaharjuntie 20, 00200 Helsinki, Finland, and ${ }^{1}$ Jyväskylä School of Business and Economics, PO Box 35, \\ FI-40014 University of Jyväskylä, Jyväskylä, Finland \\ Corresponding author email: mirva.peltoniemi@jyu.fi
}

\begin{abstract}
The growing popularity of explaining firm performance through dynamic capabilities has motivated plenty of conceptual development in the field. However, empirical approaches to measuring dynamic capabilities have so far not been under comprehensive scrutiny. The authors; purpose is to assess the extent to which different ways of measuring dynamic capabilities in quantitative studies correspond to the theoretical essence of the concept, and develop recommendations for future research. They find that four types of operationalizations have been used: (1) managers' evaluations; (2) financial data; (3) company's experience, actions and performance; and (4) managers' or employees' experience, actions and performance. Based on their analysis, the authors provide eight recommendations for future research that relate to identifying ordinary and dynamic capabilities, avoiding common method bias, taking into account the quality and fitness rather than the quantity of dynamic capabilities, and acknowledging the cumulativeness of dynamic capabilities through the use of longitudinal data. They conclude that refining the dynamic capability operationalizations would help to formulate competing hypotheses and to increase the theoretical precision of the field.
\end{abstract}

\section{Introduction}

Dynamic capabilities have gained significant prominence in strategic management research. This is manifest in the multiple literature reviews that map the theoretical developments and empirical research results related to dynamic capabilities (Ambrosini and Bowman 2009; Barreto 2010; Di Stefano et al. 2010; Easterby-Smith et al. 2009; Helfat and Winter 2011; Pavlou and El Sawy 2011; Peteraf et al. 2013; Teece 2007; Vogel and Güttel 2013; Wang and Ahmed 2007). Such reviews have identified conceptual challenges for the development of the field, some of which have been resolved in recent work (e.g. Di Stefano et al. 2014; Felin et al. 2012; Peteraf et al. 2013; Teece 2007, 2012). Empirical challenges, in contrast, have been left with much less attention. Some reviews have pointed to problems in

The authors would like to thank Teppo Felin, Juha-Antti Lamberg and three anonymous reviewers for constructive comments on earlier drafts. the research designs of empirical dynamic capabilities studies (Arend and Bromiley 2009; Pavlou and El Sawy 2011). However, we still lack a systematic review of how dynamic capabilities are operationalized. To address this gap, we ask the following three questions: (1) How are dynamic capabilities measured? (2) To what extent do the measures correspond to the theoretical essence of dynamic capabilities? (3) How should the operationalizations of dynamic capabilities be developed in future studies? ${ }^{1}$

We argue that a better understanding of operationalizations could advance dynamic capabilities research,

\footnotetext{
${ }^{1}$ We use the term 'operationalization' to refer exclusively to devising quantitative measures for a phenomenon that cannot be measured directly. Initially, we also included qualitative studies in the review. However, we realized that they represent a wide variety of approaches and differ greatly from quantitative studies in their research design, data and interpretation. Therefore, we decided to exclude them, and believe that the methods used to observe dynamic capabilities in qualitative studies deserve a review of their own.
} 
because a strong link between constructs and their empirical measures is necessary for theory development (Venkatraman and Grant 1986). Since theoretical definitions of the constructs within the resource-based view are often all-inclusive and elastic (e.g. Kraatz and Zajac 2001; Priem and Butler 2001; Williamson 1999), operationalizations provide a means for understanding what researchers specifically mean by dynamic capabilities. ${ }^{2}$ In the context of management research, Yaniv (2011, p. 590) has gone so far as to state that 'a theoretical construct has no value if it is not reducible to specific observations'. Looking at researchers' uses of different empirical measures can also shed light on their theoretical stances and help evaluate how well the theoretical construct works in different empirical settings (Berg 1995, p. 23). Moreover, operationalizations are also central for practitioner relevance: dynamic capabilities cannot be purposefully developed or assessed if there is uncertainty over how they are manifest in the empirical world. Operational validity depends on 'the ability of the practitioner to implement action implications of a theory by manipulating its causal (or independent) variables' (Thomas and Tymon 1982, p. 348), and hence a sound understanding of the relevant variables is essential if dynamic capabilities are to be developed systematically.

We begin this review by defining the theoretical essence of dynamic capabilities based on highly cited and influential theoretical contributions. This allows us to compare the operationalizations used with the theoretical ideal. We find that the essence of the dynamic capabilities construct consists of a distinction between ordinary and dynamic capabilities (e.g. Eisenhardt and Martin 2000), the role of performance as an indirect outcome of dynamic capabilities (e.g. Zahra et al. 2006), the importance of whether firms possess certain types of dynamic capabilities rather than how much of a dynamic capability they possess (e.g. Eisenhardt and Martin 2000; Teece et al. 1997), and focus on change over time (e.g. Winter 2003). These characteristics give us ample ad-

\footnotetext{
${ }^{2}$ We do not provide an exact definition of dynamic capabilities ourselves owing to the following logic: we review studies that analyze a phenomenon that is explicitly identified in the study as dynamic capabilities, regardless of the theoretical definition for dynamic capabilities that the study provides. However, we discuss the 'essence' of the dynamic capabilities construct - that is, certain key characteristics most often posited for the construct in prior research, and subsequently analyze how the different operationalizations adhere to this essence.
}

vice as to how dynamic capabilities should be measured. We then review empirical dynamic capabilities studies and identify 232 distinct operationalizations of dynamic capabilities, which we classify into four categories: (1) managers' evaluations; (2) financial data; (3) company's experience, actions and performance; and (4) managers' or employees' experience, actions and performance. Finally, we offer eight recommendations for future research on how operationalizations of dynamic capabilities can best capture the theoretical essence of the construct.

This study joins a growing stream of reviews evaluating operationalizations in management research (Karren and Barringer 2002; Lohrke et al. 2010; Venkatraman and Grant 1986), but is the first to concentrate on the operationalizations of dynamic capabilities.

\section{The essence of dynamic capabilities}

In defining the essence of the dynamic capabilities construct, the key theoretical studies offer ample advice as to how dynamic capabilities should be measured. In order to approach the essence of the construct in a systematic manner, we have followed the framework of Di Stefano et al. (2014) on the five key structural components that define dynamic capabilities, including their object (what is the object of the action of dynamic capabilities), aim (what is their goal), nature (what they fundamentally are), agent (who exerts them) and action (what do they do). Below, we discuss these key characteristics of dynamic capabilities and their implications for empirical measurement.

\section{Dynamic and ordinary capabilities}

Dynamic capabilities literature makes a conceptual distinction between ordinary capabilities and the firm's broad resource base, on the one hand, and dynamic capabilities, on the other. Ordinary capabilities (also called operational or 'zero order' capabilities) determine how a firm makes its living at the moment, whereas dynamic capabilities enable the firm to change (Winter 2003; Zollo and Winter 2002). Ordinary capabilities enable operational effectiveness, whereas dynamic capabilities enable sensing and seizing new business opportunities (Teece 2007). Dynamic capabilities create opportunities for new value-creating strategies through modifying ordinary capabilities (Eisenhardt and Martin 2000).

In consequence, in order to operationalize dynamic capabilities, there is a need to identify the object of 
action, i.e. the ordinary capabilities and resources that are being changed. This is challenging, since ordinary and dynamic capabilities are locally defined (Winter 2003), the line between them is 'unavoidably blurry' (Helfat and Winter 2011), and capabilities may have both ordinary and dynamic purposes (Zahra et al. 2006). However, making an empirical distinction between ordinary capabilities that change and dynamic capabilities that cause the change is indispensable for avoiding tautological arguments (see discussion below on dynamic capabilities and performance).

Existing research also differentiates dynamic capabilities from product-market positions (Teece et al. 1997), ad hoc problem-solving (Winter 2003) and improvisation (Zahra et al. 2006). Productmarket positions may be static manifestations of underlying dynamic capabilities, but they signal how a firm is playing the game rather than what it has to play with. Ad hoc problem-solving and improvisation, in contrast, confer dynamism, but differ from dynamic capabilities in being autonomous unplanned actions with a low maintenance cost (i.e. 'fire-fighting') rather than an organized capability that the firm could employ over and over again. Hence, planned and repeatable action is a necessary characteristic of dynamic capabilities and should also be considered in their operationalization.

\section{Dynamic capabilities and performance}

The purpose of dynamic capabilities research is to explain sources of competitive advantage (Teece 2007; Teece et al. 1997). This means that firm performance is a key component of the theory and usually seen as the ultimate aim of dynamic capabilities. Dynamic capabilities change ordinary capabilities or the firm's broader resource base, and this change may finally cause a change in performance. Therefore, dynamic capabilities cannot explain performance, but rather changes in performance (i.e. $\Delta$ performance).

There has been criticism of tautology in identifying firms that exhibit superior performance and then accrediting performance to the dynamic capabilities the firms possess (e.g. Priem and Butler 2001; Williamson 1999). To overcome this risk, several scholars have suggested that dynamic capabilities should be observed by the changes they effect in a firm's resource base (Eisenhardt and Martin 2000; Teece 2007; Zahra et al. 2006). Such changes then may or may not improve firm performance. Hence, the possession of dynamic capabilities does not necessarily lead to higher performance, but the performance outcomes are dependent on, first, the quality of the ordinary capabilities that the dynamic capabilities alter (Zahra et al. 2006) and, second, the evolutionary fitness of such capabilities (Helfat et al. 2007). Superior dynamic capabilities may not lead to superior performance if the operational capabilities are considerably under par. This scenario might take place, for example, when a firm enters a new product segment without relevant experience and hence relevant segment-specific ordinary capabilities. Moreover, superior dynamic capabilities may lead poor evolutionary fitness even when technical fitness is high (Helfat et al. 2007). This means that a firm's capabilities may be exceptional in an absolute sense (e.g. the speed and efficiency of car production), but not be appropriate in the market environment (e.g. failure to produce energy-efficient cars).

\section{Uniqueness and level of analysis of dynamic capabilities}

Our third criterion for operationalizing dynamic capabilities addresses their nature: more specifically, whether they are seen as unique abilities or as routines that can be adopted by any firm; as well as whether they are concerned with individual managers or the organization as a whole (i.e. who is the key agent that exerts them).

Teece et al. (1997) suggest that dynamic capabilities are unique to the firm. This implies that, when dynamic capabilities are operationalized, they should be measured by their type (e.g. What kind of a dynamic RD capability does the firm have?) or their existence (Does the firm have a particular type of dynamic R\&D capability?). If dynamic capabilities are unique to each firm, they logically cannot be studied by comparing their quantity or amount between firms (How much of a dynamic R\&D capability does each firm in this sample have?).

In contrast, Eisenhardt and Martin (2000) state that dynamic capabilities are relatively similar across firms (so-called 'best practices') and describe them via various examples of particular routines, such as ways of communicating within the organization, managing R\&D and performing acquisitions. ${ }^{3}$ When applied to the question of empirical measurement of

\footnotetext{
${ }^{3}$ As discussed by Peteraf and colleagues (2013), the difference in Teece and colleagues' and Eisenhardt and Martin's conceptualizations may be due to different views on environmental dynamism. Peteraf and colleagues' paper solves the apparent contradiction through a contingency model: in high-velocity markets, dynamic capabilities may be best
} 
dynamic capabilities, however, the implications are the same as those of Teece et al.'s (1997) paper. Also Eisenhardt and Martin's (2000) logic of best practices suggest that dynamic capabilities should not be measured by their quantity, but rather through a binary variable: a firm either has a best practice, process or routine constituting a dynamic capability or it does not. Hence, if a researcher wishes to compare the dynamic capabilities in a sample of firms, he/she should first identify a set of best practices and then look at which firms employ which ones. This would enable building a dynamic capability 'profile' for each firm that could then be used as a basis for comparison or empirical tests. Such a dynamic capability profile would also allow researchers to study dynamic capabilities as multidimensional constructs (Barreto 2010).

Regardless of their differences regarding the question of uniqueness of dynamic capabilities, both Teece et al. (1997) and Eisenhardt and Martin (2000) see dynamic capabilities as an organization-level variable. However, Di Stefano et al. (2014) also identify theoretical studies that emphasize the role of managers in building or deploying dynamic capabilities (e.g. Galunic and Eisenhardt 2001; Zahra et al. 2006). This difference is potentially also reflected in the empirical approaches and operationalizations. So far, it seems that organization-level theoretical definitions of dynamic capabilities are more prevalent (Di Stefano et al. 2014).

\section{Change and learning}

Dynamic capabilities literature underscores that dynamic capabilities are fundamentally concerned with change and learning (Winter 2003), which comprise the action of the theory. In order to study change, one needs longitudinal data (this point was also highlighted by Arend and Bromiley (2009)). Moreover, information concerning inputs and outputs would be valuable in order to tap into the effectiveness of the dynamic capabilities employed. Therefore, dynamic R\&D capabilities, for example, could be evaluated based on the outputs (e.g. patents or new products) that are achieved in relation to the investments made, rather than only looking at investment levels or number of patents and new products.

Prior experience is often needed for accumulating dynamic capabilities. However, there are limits to

conceptualized as simple rules and processes; while in moderate-velocity markets, they may be manifest in best practices. how useful such experience may be. If many aspects in the environment change simultaneously, managers will not be able to make sense of cause-effect relationships and may be unable to transform experience into meaningful learning (Eisenhardt and Martin 2000; Teece et al. 1997). Hence, experience should be appropriately paced. In addition to the pacing of experience, meaningful learning requires knowledge articulation and knowledge codification ${ }^{4}$ (Zollo and Winter 2002).

Moreover, dynamic capabilities research highlights trajectories and paths in capability accumulation (Eisenhardt and Martin 2000; Teece et al. 1997). Brown and Eisenhardt (1997) use the term 'sequenced steps'. This means that the order in which different types of experience come and their combinations matter in capability accumulation (e.g. acquisitions differ in terms of size, geography, relatedness to a firm's established businesses). Eisenhardt and Martin (2000, p. 1115) state that 'experience in closely related, but different situations, is particularly effective in sharpening dynamic capabilities'. Therefore, experience should not be measured solely by its quantity, but also by its variety and fitness relating to the situation that the firm is facing. In summary, in addition to quantifying experience, empirical research should control for how the firm makes use of its experience in order to learn, and record the different experience paths that firms have faced over time.

\section{Method}

In order to analyze to what extent the operationalizations of dynamic capabilities follow the essence of the concept detailed above, we undertook a systematic review of empirical dynamic capabilities studies. The first aim was to find the relevant studies and analyze what types of operationalizations they have employed. This process included a comprehensive search, winnowing down the population based on substantive and empirical relevance, and creating a categorization scheme. We followed the procedure developed by David and Han (2004) and Newbert (2007) in identifying prior empirical studies for our review, and will next describe the process in detail.

First, we searched for articles in the ISI Web of Knowledge Social Sciences Citation Index (SSCI),

\footnotetext{
${ }^{4}$ This relates to experiential learning theory, which suggests that, in addition to concrete experience, abstract conceptualization, reflexive observation and active experimentation are required for learning (Kolb et al. 2000).
} 
which begins indexing from year 1956, by the following procedure (the search was conducted in May 2016 and the last year included was 2015):

1. Ensure substantive relevance by requiring that articles contain the words 'dynamic' and 'capabilit*,5 in the title or abstract. Further ensure quantitative empirical content by requiring that articles also contain at least one of the following words in title, abstract or keywords: 'data', 'empirical, test*', 'statistical, finding*', 'result', 'results', 'evidence', 'quantitative', 'survey*' or 'investigat*', 6

2. Read through the abstracts and discard ones that do not indicate quantitative empirical work on dynamic capabilities; by for example mentioning specific dynamic capabilities studied or quantitative methods employed. Qualitative studies and case studies with no quantitative measures were also discarded at this point. Following Lee (2009), abstracts were read and first given an initial evaluation of relevance on the following scale: $(\mathrm{A})=$ directly relevant; $(\mathrm{B})=$ partially relevant; and $(\mathrm{C})=$ less relevant. ${ }^{7}$ All abstracts were read by both authors and those for which at least one author gave an (A) were chosen for the next step, in order to avoid missing potentially relevant articles.

3. Retrieve full text versions of the remaining articles.

4. Read through the articles and discard those that do not quantitatively study constructs explicitly labeled dynamic capabilities. At this stage, the analysis was rigorous: an article was included in the final sample only if it (a) discussed at least one construct that was explicitly identified as a dynamic capability,(b) specified how its amount,

\footnotetext{
${ }^{5}$ We did not simply use 'dynamic capabilit*' in order to also include more specific constructs such as 'dynamic marketing capabilities'. The search term resulted in a larger number of articles that were not relevant for our study (which were later excluded in our procedure), but also prevented us from missing relevant articles.

${ }^{6}$ We added the keywords 'quantitative', 'survey*' and 'investigat*' to those of David and Han (2004) and Newbert (2007) to avoid missing relevant articles, and changed their 'result*' to 'result' and 'results' in order to exclude the articles that only contained the word 'resulting' or 'resulted'.

${ }^{7}$ Specifically, we used the following definitions of relevance: (A) abstract indicates that article will most probably include operationalizations of dynamic capabilities; (B) abstract indicates dynamic capability theme, but article will probably not include operationalizations of specific dynamic capabilities; (C) abstract does not indicate dynamic capabilities theme or quantitative empirical analysis.
}

existence or type can be inferred from empirical data (i.e. operationalized it) and (c) utilized this operationalization on quantitative data by forming variables indicating the dynamic capability's amount, type or existence. Hence, we excluded articles that included only simulations, studied capabilities that were not identified as dynamic, studied constructs that could be titled dynamic capabilities, but that were not explicitly identified as such (e.g. absorptive capacity or 'innovative capabilities'), or presented measures of dynamic capabilities, but did not use them on empirical data. We also excluded studies that, for example, 'applied', 'underpinned their work with' or 'drew theoretical support from' the dynamic capabilities 'view', 'literature', 'approach', 'logic' or 'perspective' without presenting operationalizations of specific dynamic capabilities.

In the end, we were left with 144 articles (see Table 1, and Table S1 in the Supporting Information), which we consider a relatively low number. In our view, this may indicate that, while the ideas of dynamic capabilities research have been pervasive, operationalizing the dynamic capabilities concept has proved more challenging.

For each of the 144 articles, we identified all the theoretical definitions of individual constructs that were named dynamic capabilities, and the operationalizations and specific variables that were formed to indicate the amount, existence or type of each dynamic capability. These definitions were collected in a data sheet. We also included in the data sheet specific information about the hypotheses of the reviewed study, the independent or dependent variables that were hypothesized to be associated with the dynamic capability variable, ${ }^{8}$ and the data from which the dynamic capability variables were derived (e.g. survey responses or patent counts). All unclear cases were read by both authors and discussed. The number of operationalizations of dynamic capabilities in the 144 articles ranged from 1 to 12 per article (see Cai and Tylecote 2008), and the procedure resulted in a list of 232 distinct operationalizations of dynamic capabilities.

Having collected all the relevant information concerning the 232 operationalizations of dynamic capabilities, we developed a categorization scheme. It consists of two main factors: variable type and

\footnotetext{
${ }^{8}$ We followed Zahra et al. (2006), who emphasize the need to differentiate between dynamic capabilities and their antecedents and consequences.
} 


\begin{tabular}{lll}
\hline Filter & Description & $\begin{array}{l}\text { Article count remaining after } \\
\text { applying the filter }\end{array}$ \\
\hline 1 & $\begin{array}{l}\text { Search for all articles with 'dynamic', 'capabilit*', and at least one of the 11 } \\
\text { words indicating empirical content in title or abstract in ISI Web of Knowledge } \\
\text { Social Sciences Citation Index (SSCI), 1956-2014 } \\
\text { Read through the abstracts and discard ones that do not indicate quantitative } \\
\text { empirical work on dynamic capabilities }\end{array}$ & 1106 \\
3 & $\begin{array}{l}\text { Retrieve full text versions of articles } \\
\text { Read through the articles and discard those that do not quantitatively study } \\
\text { constructs explicitly labeled dynamic capabilities }\end{array}$ & 311 \\
\hline
\end{tabular}

adata, empirical, test*, statistical, finding*, result, results, evidence, quantitative, survey* or investigat*.

data type. We first focused on the variable types used in operationalizing dynamic capabilities - that is, whether each variable was an independent, dependent, mediating, moderating or control variable. Out of the 232 dynamic capability variables identified, 119 were independent, 58 dependent, 41 mediating, 4 moderating, and 10 a combination of variable types.

Next, we turned our attention to data types. To create the categories for data types, we relied on a grounded theory type of process (Strauss 1987). While we were reading the studies, we made meticulous notes on the data sheet concerning the data types. After reading all the articles, we began to analyze the data types and to assign them to emerging categories. These categories were modified and discussed between the authors until we had a classification that was able to describe the variation present in our 'data'. For example, we first had 'R\&D expenditure' and 'Other financial data' as separate categories. However, we realized that in studies using financials, these two often overlapped, and we decided to combine them and other inherently numerical data on company finances to the 'Financial data' category. Similarly, the emergent categories of 'New innovations/new products launched', 'External collaboration', 'Experience (e.g. in years)' and 'Other competitive actions' were first merged into 'Competitive actions or strategies' and 'Experienceor performance-based measures'. Finally, discussions led to the combination of experience and actions under one category, 'Company's experience, actions and performance', as it turned out to be impossible to discern logically between past experience and past actions. ${ }^{9}$ We also found that some of the operationalizations looked at company-level topics (e.g.

\footnotetext{
${ }^{9}$ We are grateful to an anonymous reviewer for nudging us in this direction.
}

patents, acquisitions, alliances or adoption of specific processes), while others had measures specifically related to the company's managers or employees (e.g. their education level or training they had undertaken). Hence, we still split out the category 'Dynamic capability operationalized using managers' or employees' experience, actions and performance'.

Operationalizations in the above-mentioned three categories are based on objective, inherently numerical information - no matter whether it is extracted from secondary sources or provided by managers or other employees of the firm. While surveys are sometimes used to collect data for these operationalizations, the answers are in principle verifiable from other sources, and a survey is used mainly because it is an economical way to gather the data (e.g. Brouthers et al. 2008; Uhlenbruck 2004). However, a fourth category that bases the dynamic capability variable on managers' subjective survey answers soon emerged from the data. In these operationalizations, managers' answers are not verifiable from other sources, because the information does not exist outside the managers' thoughts and intentions, or because the sought-after variable is particularly information-intensive, organizationally embedded or complex. In these types of studies, managers have been asked, for example, to rate their firms' proficiency in new product development and adaptation of technology related to their competitors (McKelvie and Davidsson 2009).

One challenge in the categorization was to differentiate between this category 'manager's evaluations' and the above-mentioned 'company's experience, actions and performance' in studies where managers were surveyed on firm operations. To make a clear distinction, we established that surveys asking about what the firm does fall under 'company's experience, actions and performance' and surveys asking about how well the firm does particular things, or whether 
the firm has the ability to do a specific thing, fall under 'manager's evaluations'.

Hence, in the end we were left with four categories with respective protocol descriptions. After agreeing on the categorization scheme, the two authors worked independently in categorizing the operationalization instances. When there was disagreement, it was resolved by discussion, and no disagreements remained after this stage. The final categories and the categorization protocol descriptions were as follows:

1. Dynamic capability operationalized by managers' evaluations (155 of the 232 instances): operationalizations are based on managers' views and evaluations concerning how well their firm performs particular tasks or how good their firm's ability in given tasks is, either relative to competitors or in an absolute sense.

2. Dynamic capability operationalized using financial data (9 instances): operationalizations are based on numerical data that can be found in the firm's account books, profit and loss statement or balance sheet.

3. Dynamic capability operationalized through a company's experience, actions and performance (54 instances): operationalizations track the past experience (e.g. number of years operated in a given product market), actions (e.g. number of product introductions or adoption of a particular innovation model) and performance (e.g. number of patents or number of industry awards) of the firm. ${ }^{10}$

4. Dynamic capability operationalized using managers' or employees' experience, actions and performance (14 instances): operationalizations track the characteristics and actions of executives or employees (e.g. education or publishing activity).

All the studies reviewed (144 in total) are listed in Table S1 in the Supporting Information. Table S1 also presents the categorization of all the 232 dynamic capability operationalizations in them to the four data types explained above. We next introduce the four different data types in more detail.

\footnotetext{
${ }^{10}$ The difference between financial data and experience, actions and performance data is that the former is produced for accounting purposes and follows legal requirements, whereas the latter is a company's internal strategic information or market information, which can be collected and applied in a more flexible manner.
}

\section{Four types of dynamic capabilities operationalizations}

In the following sub-sections, we explain how each of the four data types have been used in operationalizing dynamic capabilities, and hence answer the question: (1) How are dynamic capabilities measured? On the basis of listing the data type and variable type of each dynamic capability operationalization, an integrative abstraction was also made. Table 2 presents schematic diagrams of the causal structures of studies using the four different data types.

\section{Managers' evaluations}

These operationalizations are based on managers' views and evaluations concerning how well their firm performs particular tasks or how good their firm's ability in given tasks is, either relative to competitors or in an absolute sense. This is typically done on a Likert-type scale by asking the managers to evaluate their company's proficiency in, for example, 'Setting up new distribution channels', 'Developing new pricing strategies' (Danneels 2008) or ability to 'acquire entirely new skills and resources, integrate them with its own internal capacity, and produce innovative products' (Lew et al. 2013); or asking them to evaluate statements such as 'We are often one of the first in our industry to detect technological developments that may potentially affect our business' or 'We generally respond very quickly to technological changes in the environment' (Chen and Lien 2013). These studies typically study either the effect of dynamic capabilities on firm performance or the effect of firm or owner characteristics on dynamic capabilities. These operationalizations are listed in detail in Table S2 in the Supporting Information.

\section{Financial data}

These operationalizations are based on numerical data that can be found in the firm's account books, profit and loss statement or balance sheet. Examples include R\&D expenditure (Helfat 1997; Hsu and Wang 2012; Liao and Rice 2010; Narasimhan et al. 2006; Rothaermel and Hess 2007; Rothaermel and Hill 2005), current assets (Rothaermel and Hill 2005), marketing expenditure (Narasimhan et al. 2006) and sales distribution over product markets (Lee et al. 2010). These are used to measure the dynamic capabilities status of firms at the time of the data capture, and the dynamic capabilities operationalized in this 
Table 2. Causal structures in dynamic capabilities research ${ }^{a}$

\begin{tabular}{|c|c|c|c|}
\hline Data type & $\begin{array}{l}\text { Antecedents of } \\
\text { dynamic } \\
\text { capabilities }\end{array}$ & $\begin{array}{l}\text { Dynamic capability } \\
\text { operationalizations }\end{array}$ & $\begin{array}{l}\text { Outcomes of dynamic } \\
\text { capabilities }\end{array}$ \\
\hline $\begin{array}{l}\text { Managers' } \\
\text { evaluations }\end{array}$ & $\begin{array}{l}\text { Firm's, its owner's, or } \\
\text { the environment's } \\
\text { Characteristics }\end{array}$ & $\begin{array}{l}\text { 'How well do you do } \\
\text { specific things?' }\end{array}$ & $\begin{array}{l}\text { 'How well do you } \\
\text { perform in } \\
\text { general?' }\end{array}$ \\
\hline Financial data & $\begin{array}{l}\text { Prior investments; } \\
\text { Assets }\end{array}$ & $\begin{array}{l}\text { R\&D expenditure; } \\
\text { Financial position }\end{array}$ & $\begin{array}{l}\text { Sales; ROA; Market } \\
\text { share }\end{array}$ \\
\hline $\begin{array}{l}\text { Company's } \\
\text { experience, actions } \\
\text { and performance }\end{array}$ & $\begin{array}{l}\text { Prior experience; } \\
\text { Work organization } \\
\text { and team composition }\end{array}$ & $\begin{array}{l}\text { Experience/position } \\
\text { in a market; New } \\
\text { products; } \\
\text { Acquisitions; } \\
\text { Alliances; Patents; } \\
\text { Awards }\end{array}$ & $\begin{array}{l}\text { Survival; Patents; } \\
\text { Sales; Profitability; } \\
\text { Market share gain; } \\
\text { New entry }\end{array}$ \\
\hline $\begin{array}{l}\text { Managers' or } \\
\text { employees' } \\
\text { experience, actions } \\
\text { and performance }\end{array}$ & & $\begin{array}{l}\text { Employees' } \\
\text { credentials and roles; } \\
\text { Managers' attention }\end{array}$ & $\begin{array}{l}\text { Patents; } \\
\text { Innovativeness; } \\
\text { Diversification; } \\
\text { Sales }\end{array}$ \\
\hline
\end{tabular}

${ }^{a}$ On each row the left-hand column describes the independent variables appearing in studies where the dependent variable is a dynamic capability. The middle column describes the dynamic capability variables (both independent and dependent) and their operationalizations. The right-hand column shows the dependent variables from studies where the independent variables include dynamic capabilities.

The arrows depict the relationships between the variables. Arrows A1 to $\mathrm{C} 1$ depict the hypothesized relationships between variables in studies in which a dependent variable is a dynamic capability. Arrows A2 to D2 depict the hypothesized relationships between variables in studies in which an independent or mediating variable is a dynamic capability. Arrows A3 and C3 depict the instances in which the dynamic capability variable is a moderating or mediating one. When there are fewer four operationalization instances for a particular connection between variables, the arrow is drawn with a dashed line.

way are usually hypothesized to have an effect on various performance measures such as ROA, sales or market share. These operationalizations are listed in detail in Table S3 in the Supporting Information.

\section{Company's experience, actions and performance}

These operationalizations track the past experience, actions and performance of the firm (see Table S4 in Supporting Information). Experience is measured, for example, in years operated in a specific geographic market and the number of countries the firm has operated in (Brouthers et al. 2008), or through a comparison of industries based on the extent to which pre-entry experience helps firms to learn after entry and hence increase total factor productivity (Balasubramanian 2011). The actions used to measure dynamic capabilities include acquisitions (Rothaermel and Hess 2007; Uhlenbruck 2004), alliances (Doving and Gooderham 2008; Rothaermel and Hess 2007), entry to new market (King and Tucci 2002), entry timing to new market (Franco et al.
2009), market exit (Moliterno and Wiersema 2007), product launch (Shamsie et al. 2009), having particular procedures in place (Doving and Gooderham 2008; Heimeriks et al. 2012), having flexible HR practices (Martinez-Sanchez et al. 2011), hiring employees to explore new markets (Groysberg and Lee 2009) and performing particular types of innovations (Ganter and Hecker 2013). Performance measures include patents (Anand et al. 2010; Bogner and Bansal 2007), awards received by the firm's products (Lampel and Shamsie 2003), technological sophistication (Stadler et al. 2013), market shares (Tsai et al. 2011), and manufacturing cycle time (Macher and Mowery 2009). The more of these a firm has achieved or performed in the past, the more of a particular dynamic capability it is considered to have. These types of operationalizations are based on the logic that, in order to do something, the firm has to have a capability for doing it. As a consequence, the more of the capability the firm has, the more of the action in question it performs. 
The dynamic capabilities measured through these types of firm-level observations are seen as having an effect on performance indicators, including sales and profitability, market entry and market shares, and survival. These operationalizations are listed in detail in Table S4 in the Supporting Information.

\section{Managers' or employees' experience, actions and performance}

These studies operationalize the construct of dynamic capabilities through managers' or employees' experience, actions and performance. They build variables related to a firm's human resources, e.g. the number of executive positions (Fortune and Mitchell 2012), the percentage of short-term hires (Martinez-Sanchez et al. 2011), top manager's attention to new opportunities (Eggers and Kaplan 2009; Kaplan 2008) and employees' credentials, such as their education level (Doving and Gooderham 2008), participation in training (Kok and Ligthart 2014), previous professional experience (Lampel and Shamsie 2003) or scientific achievements (Rothaermel and Hess 2007) (see Table 7). The approach in these studies is typically summative: the larger the number of a firm's, say, qualified employees, the more it is seen to possess dynamic capabilities. The dynamic capabilities operationalized in this way are hypothesized to have an effect on performance indicators including sales, diversification and patents. These operationalizations are listed in detail in Table S5 in the Supporting Information.

\section{Critical assessment of the operationalizations}

We next compare the dynamic capability operationalizations reviewed with the essence of the dynamic capabilities construct, and develop recommendations for future research. In other words, having answered the first research question (How are dynamic capabilities measured?), we proceed to answer the other two: (2) To what extent do the measures (of dynamic capabilities) correspond to the theoretical essence of dynamic capabilities? (3) How should the operationalizations of dynamic capabilities be developed in future studies?

In order to proceed in a structured manner, we position our recommendations in relation to the theoretical elements of the dynamic capabilities concept outlined in the section 'The essence of dynamic capabilities'. The recommendations and their connections to the operationalization types and more general operationalization actions are synthesized in Figure 1. Recommendations 1, 2, 3 and 6 are relevant for quantitative dynamic capability research, regardless of the specific operationalization used. Recommendations 4 and 5 are of importance, independent of which operationalization type is used, but they lend a special relevance to 'financial data' and 'managers' evaluations' types of operationalizations, respectively. Recommendations 7 and 8 are relevant for specific types of operationalizations, as detailed in Figure 1 and discussed below.

\section{Dynamic and ordinary capabilities}

The majority of studies reviewed do not make a distinction between dynamic capabilities (the ones that create change) and ordinary capabilities or resources (the ones that change). This issue is common for all four operationalization types. The institutionalization of the study design where ordinary capabilities or resources are not specified is unfortunate, because it limits the scope of research questions that would be interesting for advancing the dynamic capabilities theory. Making a clear distinction between dynamic and ordinary capabilities in empirical study designs would enable researchers to look at the speed of change, and the effective matching of specific ordinary and dynamic capabilities. How fast can dynamic capabilities create a substantial change in ordinary capabilities? What types of ordinary capabilities are most susceptible to change by dynamic capabilities? Which dynamic capabilities should a firm deploy to induce change quickly in a specific set of ordinary capabilities? So far, these types of questions have remained largely untouched. While Helfat and Winter (2011) note that the difference between dynamic and ordinary capabilities is 'unavoidably blurry', they, too, encourage researchers to distinguish carefully operational and dynamic capabilities: dynamic ones promote economically significant change (no matter what the direction and speed of the change), some have principally operational purposes, and still others may have a dual purpose.

Recommendation 1: Identify the ordinary capabilities or resources that are changed by dynamic capabilities.

Among the operationalizations reviewed, one way to capture the difference and relationship between a firm's ordinary capabilities and its dynamic ones 


\section{Consider when choosing and refining the operationalization type}

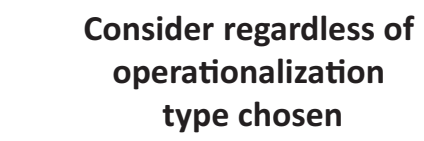

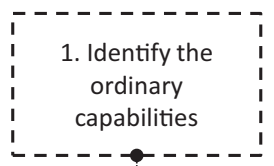

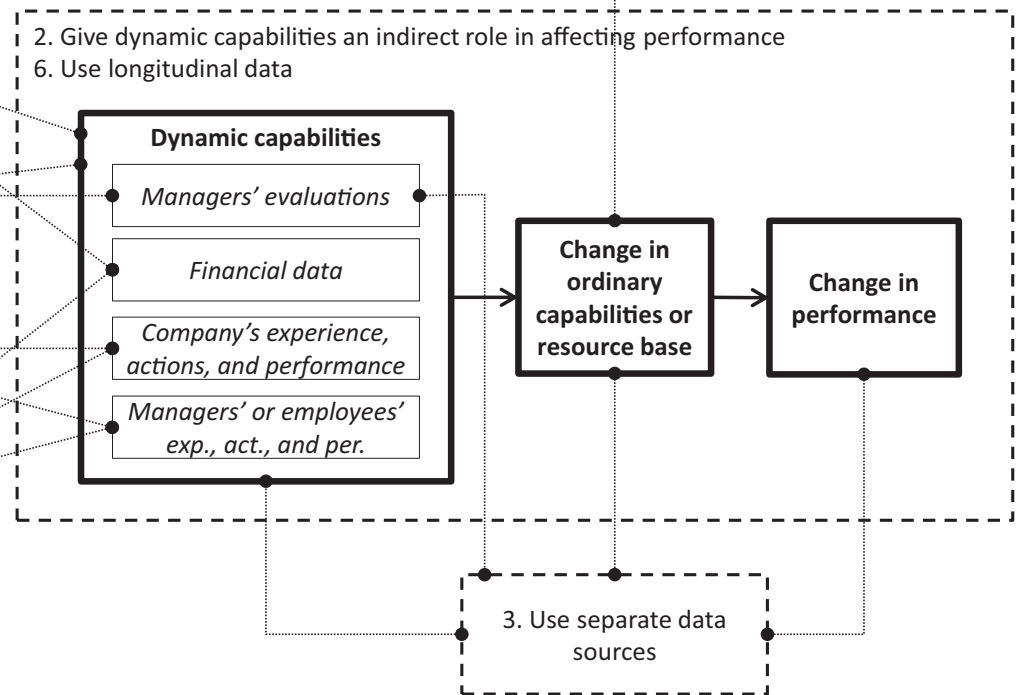

Figure 1. Synthesis of recommendations

has been to look at the firm's employees' ability to create change in the firm's ordinary capabilities. For example, Bhattacharya et al. (2005) studied the dynamic capabilities of 'employee skill flexibility' and 'employee behaviour flexibility' through asking managers for their views on the extent to which their firm's employees can be utilized in many types of jobs (since they have multiple skills or the firm is good at training them), or are flexible and willing to change their working habits when the external environment presents a need to change. As Bhattacharya et al. (2005) note, these measures aim to tap into the firm's proficiency in 'adapting employee attributes - such as knowledge, skills, and behaviors - to changing environmental conditions'. Similarly, in the study by Groysberg and Lee (2009), a firm is seen to provide evidence of dynamic capabilities if a previously well-performing employee is hired to a new role aimed at exploring new markets. Although potentially applicable only in a limited number of contexts, these operationalizations have the advantage of distinguishing between zero-order resources and capabilities (the individual employees per se and their ability to take care of their daily tasks), and dynamic capabilities (the firm's ability to change the ways in which it uses its employees' skills). More general examples of identifying ordinary capabilities changed by dynamic capabilities are offered by Wilhelm et al. (2015), who examine the effect of dynamic capabilities on operating routines, and by Karimi and Walter (2015).

\section{Dynamic capabilities and performance}

We have observed in our analysis that the main body of empirical dynamic capabilities research aims to show that dynamic capabilities directly affect firm performance. This tendency, also noted in earlier reviews (Arend and Bromiley 2009; Barreto 2010; Helfat et al. 2007, p. 42), is in conflict with the theoretical idea of dynamic capabilities having an effect on ordinary capabilities, which, in turn, have an effect on performance (Eisenhardt and Martin 2000; Teece 2007; Zahra et al. 2006). Excluding ordinary capabilities from empirical work brings about the risk that the observed performance may not be caused by dynamic capabilities. This is because the effects of dynamic capabilities on ordinary capabilities, and of ordinary capabilities on performance, are not documented. This issue is present in studies using any of the four operationalization types, but is most notable in those employing managers' evaluations, e.g. in Bhattacharya et al. (2005), Drnevich and Kriauciunas (2011), Kusunoki et al. (1998), Malik 
and Kotabe (2009), Salge and Vera (2013), Schilke and Goerzen (2010), Slater et al. (2006) and Song et al. (2005).

Recommendation 2: Give dynamic capabilities an indirect role in affecting performance.

However, some studies offer methodological solutions that take steps towards the direction suggested here. Marcus and Anderson (2006) and Capron and Mitchell (2009) expect dynamic capabilities to affect the acquisition of new capabilities, whereas Zhou and $\mathrm{Wu}(2010)$ hypothesize that strategic flexibility (a dynamic capability) moderates the effect of technological capability (an ordinary capability) on performance. Also Han and Li (2015) structure their argument so that knowledge-based dynamic capability moderates the effect of intellectual capital (a resource) on innovative performance. Moreover, Lee (2010) proposes that dynamic capabilities affect firm growth rather than performance per se; Kyrgidou and Spyropoulou (2013) posit that dynamic capabilities affect innovativeness and innovativeness affects performance; Yi et al. (2015) hypothesize that dynamic capabilities affect the speed of strategic change which affects performance; and Liao and Rice (2010) study the effect of innovation-related dynamic capabilities on sales growth rather than gross sales. These studies take into account the role of ordinary capabilities, and see dynamic capabilities as connected to changes in performance rather than directly determining performance.

Owing to the tendency to expect dynamic capabilities to affect performance directly, we know little about how dynamic capabilities moderate the effects of ordinary capabilities on performance. For example, we lack understanding of how fast dynamic capabilities can effect change in ordinary capabilities, which would allow us to determine the required time-frame in which superiority in higher-order capabilities trumps superiority in lower-order capabilities (Winter 2003). Moreover, the survey designs asking about a specific dynamic capability and overall performance leave little room for alternative explanations and for the testing of competing hypotheses. What types of dynamic capabilities are the most helpful for changing ordinary capabilities and hence creating a change in performance? Are there specific dynamic capability combinations that would be especially effective? These types of studies would also give valuable advice to managers for choosing which dynamic capabilities to invest in for the purpose of improving performance.
An additional concern relating to the relationship of dynamic capabilities and performance is that many studies using managers' evaluations suffer from common method variance (Campbell 1982; Cook and Campbell 1979). This means that the same survey responses are used to construct both the independent and the dependent variables. Among the studies that we reviewed, common method variance was present, for example, in Barrales-Molina et al. (2013), Capron and Mitchell (2009), Danneels (2008), Drnevich and Kriauciunas (2011), Fang and Zou (2010), Feller et al. (2013), Jansen et al. (2009), Kusunoki et al. (1998), Kyrgidou and Spyropoulou (2013), Lee et al. (2015), Malik and Kotabe (2009), Marcus and Anderson (2006), McKelvie and Davidsson (2009), Schilke and Goerzen (2010), Slater et al. (2006) and Song et al. (2005). In these studies dynamic capabilities scores and performance scores, or data on the antecedents of dynamic capabilities and on dynamic capabilities themselves, were both obtained from the same informants. ${ }^{11}$

A challenge facing the operationalizations based on such surveys is the tendency of people to make attributions based on their firm's overall performance, independent of which specific factors they are asked to rate. This phenomenon is vividly documented in Phil Rosenzweig's The Halo Effect (Rosenzweig 2007), in which he highlights the inclination of people to evaluate abstract and ambiguous characteristics of companies, based on tangible performance data. Hence, managers from high-performing organizations tend to rate their firm's communication practices, organizational culture, customer orientation and other such factors as strong. ${ }^{12}$ For instance, in Malik and Kotabe's (2009) study, managers are first asked

\footnotetext{
${ }^{11}$ Although it is not the focus here, we must also note the persistent concern in strategy research over how firm performance should be measured (Meyer 2005; Starbuck 2005). In most studies that we reviewed, performance was measured through financials, such as return on sales (Shamsie et al. 2009) or annual sales growth (Lee 2010). Some measures were related to the firm's staff, such as growth in the number of employees (Danis et al. 2010), or an index based on operating profit per employee, sales per employee, return on sales and cost of sales over sales (Bhattacharya et al. 2005). Still others relied on asking managers to evaluate different aspects of their firm's performance (Drnevich and Kriauciunas 2011; Malik and Kotabe 2009; Slater et al. 2006; Song et al. 2005), or to estimate future sales growth (Liao and Rice 2010).

${ }^{12}$ This effect has been documented by Staw (1975) and replicated by Downey et al. (1979) in an experiment in which teams that were told that they performed well in a financial analysis task subsequently rated their cohesiveness, influence, communication and motivation significantly
} 
to evaluate how the use of a new product technology has improved their company's performance on a collection of Likert-scale items. Thereafter, they are asked to rate their firm's organizational learning, reverse engineering practices and manufacturing flexibility - the dynamic capabilities measured in the study. The halo effect suggests that managers are not able to evaluate these items independently of each other: if managers think that the new product technology has improved their company's performance, the design of the survey directs them to attribute good performance to the dynamic capability items.

We wish to emphasize that, if dynamic capabilities are hypothesized to affect performance (whether through a moderating role or directly), their measures should be independent of performance. An example of this is Salge and Vera's (2013) study performed in hospitals, in which dynamic capabilities are measured through a survey and performance through the Hospital Standardized Mortality Ratio (HSMR). Other solutions have been introduced by Bhattacharya et al. (2005) and Julian et al. (2008), who measure dynamic capabilities via survey responses and performance via financial statements and expert ratings, respectively.

Recommendation 3: Use different sources for dynamic capabilities data and performance data.

\section{Uniqueness and level of analysis of dynamic capabilities}

The majority of the reviewed studies relied on both Teece et al. (1997) and Eisenhardt and Martin (2000) in their theoretical definition of dynamic capabilities. Hence, it appears that many researchers have not taken a clear stance on whether dynamic capabilities are unique to the firm or best practices similar across firms. As a result, it was interesting to find that the majority of the operationalizations reviewed measure dynamic capabilities by their quantity, be it managers' ratings of the amount of architectural and process capabilities (Kusunoki et al. 1998), the amount of R\&D capability proxied by R\&D expenditure (Rothaermel and Hess 2007) or the amount of transforming capabilities measured by the number of nominations and awards the firm's products

higher than teams that were told that they performed poorly - although there was no actual difference in the performance between the teams. have received (Lampel and Shamsie 2003). This tendency indicates that researchers see dynamic capabilities as something similar across firms, and therefore firms can be compared as to how much of a particular dynamic capability they have. We found this in all the four operationalization types, but the most obvious case is using standardized financial data such as $R \& D$ expenditures to measure dynamic capabilities.

We find this tendency in conflict with both the idea of unique dynamic capabilities (Teece et al. 1997) and that of dynamic capabilities as best practices (Eisenhardt and Martin 2000). Unique dynamic capabilities cannot logically be measured by comparing their amount between firms, and a best practice is something that a firm either has or does not have. We only reviewed studies that operationalize dynamic capabilities based on quantitative data; however, this does not necessarily mean that the researcher has to analyze the quantity or amount of dynamic capabilities. Quantitative data could also be used to identify the existence or types of dynamic capabilities in different firms.

In our sample, we found six exceptions to measuring dynamic capabilities by their quantity (Arend 2014; Arthurs and Busenitz 2006; Bernroider et al. 2014; Doving and Gooderham 2008; Groysberg and Lee 2008; King and Tucci 2002). These studies look at whether a firm possesses a particular dynamic capability by a binary variable, and hence are in line with Eisenhardt and Martin's (2000) view of dynamic capabilities as best practices. Doving and Gooderham (2008) determine the existence of internal development routines by whether a firm has devised a skills development plan; Bernroider et al. (2014) determine the level of IT governance capability by adding up the number of specified IT governance routines the firm has in place; Arthurs and Busenitz (2006) consider a firm to have a dynamic capability to address a certain risk if the risk is mentioned in its IPO prospectus; Groysberg and Lee (2009) perceive firms to possess a dynamic capability if they hire employees to explore new markets; and King and Tucci (2002) classify firms that enter a new market niche as having internal development routines. Arend (2014) used a survey in which the first questions determine whether the firm has a dynamic capability in the first place; and only the firms that are found to possess dynamic capabilities are then asked questions that aim to tap into the 'quality' of these capabilities. As discussed, the majority of studies reviewed omits the first step and directly measures 
the amount of dynamic capabilities of a sample of firms.

We also found one study that takes into account the uniqueness and firm-specificity of dynamic capabilities and hence corresponds to Teece and colleagues' (1997) conceptual definition. Bogner and Bansal (2007) measure internal knowledge management by a company's experience, actions and performance: they look at the number of new patents that the firm produces, divided by the number of its previous patents that are cited in the new patents. This definition aims to capture the firm's capability to build on its earlier discoveries when producing new knowledge, and thus manages to take into account each firm's unique R\&D path.

Measuring dynamic capabilities as something that is similar across firms and only varies by quantity makes it hard to capture their uniqueness or whether a firm possesses a particular best practice. In order to get an empirical grip on either firm-specific dynamic capabilities or common best practices, there is a need to build firm profiles that describe the dynamic capability base of a firm. Such a profile would provide a multidimensional construct (cf. Barreto 2010) detailing the qualities of a firm's unique dynamic capabilities or mapping the constellation of a firm's interdependent best practices. The tendency to measure dynamic capabilities by their quantity also makes it challenging to test Eisenhardt and Martin's (2000) and Teece and others' (1997) conceptualizations as competing hypotheses. Are unique dynamic capabilities or common best practices more effective in changing ordinary capabilities and hence performance? Does their superiority depend on the speed of change or other environmental characteristics? To what extent are different types of dynamic capabilities inimitable?

We think that in the future researchers could benefit from being explicit about which conceptualization they are following. This could be done in light of Peteraf and colleagues' (2013) contingency model, which conceptualizes dynamic capabilities as either simple rules and processes or best practices based on the level of dynamism in the environment in which a firm operates. Moreover, we believe that using multidimensional measures of dynamic capabilities (see Barreto 2010) would allow researchers to operationalize firm-specific dynamic capability profiles. This approach would increase the richness of dynamic capabilities operationalizations, and could be adapted to both unique and best practice conceptualizations.
Recommendation 4: Explicate whether dynamic capabilities are firm-specific or common best practices and operationalize them accordingly.

As noted by Di Stefano and colleagues (2014), one aspect that separates dynamic capability scholars is whether the focus of analysis is on the role of individual managers or on the organization as a whole. In the same way as theoretical studies, the empirical studies that we reviewed also seem to adhere more to the latter view; that is, they measure dynamic capabilities as an organization-level construct. This is especially true - almost by definition of the operationalizations using financial data or looking at a company's experience, performance and actions. However, most of the operationalizations based on managers' evaluations also ask managers to assess dynamic capabilities as firm-level phenomena that are somewhat independent of their own direct actions. Examples include studies that ask managers to assess their firms' proficiency in building new production facilities, recruiting engineers with new skills, understanding new technologies, and assessing the potential of new markets (Danneels 2008); or their firm's overall strategic, structural and operational flexibility (Barrales-Molina et al. 2013).

The conviction that top managers can reliably evaluate complex company-level issues on a fixed scale seems commonly accepted in dynamic capabilities research using subjective surveys. However, concerns relating to reliability may arise from asking these busy respondents to remember, weigh, predict, interpret and evaluate multiple fairly abstract issues. When evaluating their firms' overall dynamic capabilities, managers' answers may also be distorted by the willingness to give a good impression of their firm (Bertrand and Mullainathan 2001). In some studies, managers are expected to have in-depth knowledge about their competitors' internal processes (e.g. Cheng and Chen 2013; Lee 2010; McKelvie and Davidsson 2009; von den Driesch et al. 2015). For example, McKelvie and Davidsson (2009) asked CEOs to rate their firms' performance over the past three years in the 'development of new product development methods' and 'adaptation of new technologies in existing processes', compared with their two most important competitors. Collecting perceptual survey data from multiple members of the organization and using agreement measures as evidence of data validity might not solve the issue, because high agreement may only reflect the 'shared mythologies' of the members of the organization (Starbuck 2005, p. 285), or 
agreement may remain low, independent of how well the survey items are designed (Denrell et al. 2004). In this sense, surveying managers about firm capabilities in multiple areas (that is, asking them to rate multiple, logically different capabilities and their combinations) might be a more reliable approach, since it gives them the chance to give some capabilities more weight in explaining their firm's performance. This could also be one way to build the types of firmspecific dynamic capability profiles discussed above.

Regardless of the concerns raised above regarding measuring firm-level dynamic capabilities through managers' evaluations, a subjective survey may actually be a good method of measuring dynamic capabilities that are also theoretically associated with the individual manager's cognitions. However, in our review, we found only two studies in which the dynamic capability posited by the authors is indeed theoretically related to managers' subjective assessments and choices. The dynamic capability to select appropriate modes of capability sourcing (see Capron and Mitchell 2009) can also theoretically be seen to depend on managers' evaluations of their firm's capability constraints and internal social constraints. In a similar manner, von den Driesch and colleagues (2015) study how CEOs' self-evaluation, managerial tie utilization, trust and solidarity affect their firm's dynamic capabilities, as reported by the CEOs themselves.

However, operationalizations looking at managers' or employees' experience, actions or performance make an exception in that we found four of them that see individual managers as the key actors in dynamic capability development and deployment, and directly operationalize the construct in this vein. Kaplan (2008) and Eggers and Kaplan (2009) use the counts of specific words in CEOs' letters to shareholders to operationalize the dynamic capabilities of CEO attention to new opportunity and of managerial cognition, respectively. Fortune and Mitchell (2012) and Lampel and Shamsie (2003) use the number of certain types of individuals in an organization as a proxy for managerial and mobilizing capabilities.

Recommendation 5: Be consistent about the level of analysis in dynamic capabilities theory development and empirical testing.

\section{Change and learning}

The concept of dynamic capability includes the idea of capability emergence, change and accumulation over time. This suggests that longitudinal data should have an important role in all types of operationalizations of dynamic capabilities. However, among the empirical work that we reviewed, there was a relatively limited number of studies with dynamic capability operationalizations using longitudinal data (Danneels 2008; Eggers and Kaplan 2009; Franco et al. 2009; Helfat 1997; Kaplan 2008; King and Tucci 2002; Lampel and Shamsie 2003; Lee et al. 2010; Macher and Mowery 2009; Moliterno and Wiersema 2007; Rothaermel and Hess 2007; Rothaermel and Hill 2005; Shamsie et al. 2009; Zhou and Wu 2010).

Some of the studies using longitudinal data, however, leave behind the idea of capability accumulation and use observations from different years independent of each other. For example, Lampel and Shamsie (2003) split their sample of products into two time periods, and find a difference in the relative importance of particular dynamic capabilities between the time periods in determining product sales. However, they do not assign the observations of dynamic capabilities to organizations reappearing later in the data, but treat dynamic capabilities as a one-off characteristic of each product. Hence, their operationalization cannot tap into firm-specific paths in capability accumulation over time.

Change is at the heart of the dynamic capabilities theory (Winter 2003) and therefore we would also like to urge researchers to use longitudinal data, while acknowledging the difficulty of building longitudinal data sets. This would allow researchers to capture better firms' paths of capability change and accumulation, and to study incremental change facilitated by dynamic capabilities in addition to radical change (cf. Helfat and Winter 2011).

Recommendation 6: Use longitudinal data in order to capture capability accumulation and change over time.

Operationalizations based on a company's past experience, actions and performance are consistent with the idea that capabilities in general, and dynamic capabilities in particular, are built through experience (Helfat et al. 2007, p. 3). However, there is some misalignment between the definitions of dynamic capabilities highlighting their contribution to a firm's change and renewal when it faces changing conditions (e.g. Helfat and Winter 2011) and operationalizations based on firms repeating the same types of actions or accumulating similar types of experience from specific limited domains. 
Having operated longer than competitors in a given environment does not logically give a firm superior capabilities to change, and may conversely result in technological and market lock-ins as well as inertia due to path dependence (cf. Cowan and Gunby 1996; Sydow et al. 2009). The acquired capabilities may become obsolete (Agarwal 1996; Henderson 1999), and there may be other first-mover disadvantages (Lieberman and Montgomery 1998). Firms also perform many vital actions that they may never replicate (Teece 2012); and may end up performing certain actions not because they are particularly good at them, but because they are even worse at doing something else, because they blindly follow their competitors, or because constantly failing in performing the action forces them to repeat it over and over again. For example, the frequency of alliances and acquisitions (e.g. Rothaermel and Hess 2007) does not necessarily signal superior capabilities: firms may need to perform several acquisitions because they do not reach their goals with the first ones. Studies using these types of operationalizations do not typically control for whether the recorded actions have been successful, or contemplate whether it could have been a superior strategy to refrain from performing the actions - in other words, consider the appropriateness or fitness of the actions.

Also Eisenhardt and Martin (2000) highlight the need to gain experience from related but different situations to build dynamic capabilities. Steps in this direction have been taken in studies where, in addition to the number of past actions, their variety is also recorded. In Doving and Gooderham's (2008) study, the number of industries in which the firm has alliances is used as a proxy for a dynamic capability. Such an approach acknowledges that performing several actions in one domain does not necessarily contribute to a firm's ability to succeed in others. Instead of quantity, the variety of past actions builds the firm's portfolio of options for the future (Bowman and Hurry 1993), and thus contributes to its ability to respond to changing environments in a flexible manner. In addition to variety, the key to superior dynamic capabilities is their evolutionary fitness, or appropriateness, relating to the changing environment (Helfat et al. 2007). While variety of experience does not guarantee that a firm has gained dynamic capabilities with good fitness relating to the changing business environment, variety increases the firm's capacity to tackle new situations and learn. We believe that acquiring additional capabilities, no matter whether dynamic or ordinary, has decreasing cost.
Considerations of fitness would also be helpful in studies using managers' and employees' credentials to operationalize dynamic capabilities, which rely on the logic that a more educated or heterogeneous workforce is better able to modify the firm's resource base. For example, Doving and Gooderham (2008) posit that an accounting firm with more educated workers is more likely to offer complementary services in addition to mere accounting, and hence possess the capability of dynamically altering its service offering. Similarly, Martinez-Sanchez and colleagues (2011) study the dynamic capability of 'internal HR flexibility' through dividing the sum of a firm's employees covered by flexible HR practices such as training and job rotation by the total number of employees in the firm. While these types of operationalizations suit certain situations, their appropriateness may depend on the competitive situation that the firm is facing (Helfat et al. 2007). For example in cases in which the firm should go into radically new industries, a workforce with significant prior experience and education from the previous key business might even intensify resistance to change. ${ }^{13}$

Recommendation 7: Balance quantity, variety and fitness in measuring prior experience, actions, and performance.

We would also like to draw attention to the distinction between learning opportunities and learning outcomes. Many of the studies that operationalize dynamic capabilities through a company's experience, actions and performance also have the tendency to measure the quantity of a learning activity (e.g. length of experience or number of actions) rather than its effectiveness and suitability. We believe this hinders the development of the dynamic capabilities theory as it makes it impossible to find out what causes the differences in firms' different abilities to learn. From the viewpoint of strategic management literature, the interesting question is why firms that have similar learning opportunities end up with different learning outcomes. Firms' heterogeneous abilities to learn and to react to changes are at the center of dynamic capabilities theory, and such phenomena cannot be captured by comparing firms on the amount of static experience accumulated.

Experiential learning theory suggests that, in addition to concrete experience, abstract conceptualization, reflexive observation and active

${ }^{13}$ We thank an anonymous reviewer for pointing this out. 
experimentation are needed for learning to take place (Kolb et al. 2001). Studies using experience measures rarely comment on the other three components of experiential learning. In a similar vein, Zollo and Winter (2002) state that knowledge codification is an under-emphasized element in capabilities research. According to Helfat et al. (2007, p. 3), dynamic capabilities 'arise from prior learning and experience' (emphasis added), so using mere experience as a proxy for dynamic capabilities only captures one half of the whole picture. It must also be noted that not all types of experience lead to learning. For example, Eisenhardt and Martin (2000, p. 1115) note that 'The evolution of dynamic capabilities is also affected by the pacing of experience. Experience that comes too fast can overwhelm managers, leading to an inability to transform experience into meaningful learning.' Hence, the building of dynamic capabilities does not necessarily follow a classic learning curve - even though the building of non-dynamic capabilities (such as the ability to produce the same product faster and with less labor) may.

In addition to company-level experience, actions and performance, the distinction between learning opportunities and learning outcomes is important when expenditure (a special case of financial data) is used to operationalize dynamic capabilities. For example, R\&D expenditure is often used in dynamic capabilities operationalizations because it measures a firm's investment in searching for new technological solutions and business opportunities. However, there is evidence that investment in R\&D has only a weak correlation with R\&D competence (Danneels 2008). While investing in R\&D and other innovation-related activities certainly increases the probability that a firm is able to modify and extend its resource base (through, for example, launching new products), mere investment levels cannot capture firms' different abilities to make good use of the investments - in other words, the effectiveness of their activities. ${ }^{14}$

\footnotetext{
${ }^{14}$ Another way to think of this is to expect that companies invest their funds in activities of which the expected net present value is the highest. Hence, high R\&D expenditure does not signal superiority in R\&D in relation to competitors, but only higher expected returns compared with the firm's other potential investment opportunities. This means that expenditure figures do not provide information on how capable firms are in relation to each other, but they can provide information on the relative order of one firm's capabilities. If firm A invests heavily in R\&D and less so in marketing, and firm B does the opposite, we cannot deduce that $\mathrm{A}$ is more capable in $\mathrm{R} \& \mathrm{D}$ than $\mathrm{B}$. However, we can hypothesize that $\mathrm{A}$ is more
}

To take these types of operationalizations forward, it would be necessary to relate expenditure to measures of outputs of the desired dynamic processes such as patents, new products, new markets entered or business units restructured - instead of looking at expenditure or output in isolation. In such operationalizations, the more dynamically capable firms would be the ones achieving more output with less input that is, those that have learned to deal with changing situations more effectively (see Eggers 2012). This approach would also help avoid the criticized tautology of identifying firms that exhibit superior performance and crediting such performance to the firms' dynamic capabilities (e.g. Priem and Butler 2001; Williamson 1999). By examining how much change in performance is achieved with a given set of inputs, the differences between firms in their dynamic capabilities could be analyzed. This approach would also account for the negative consequences that dynamic capabilities may bring about (Zahra et al. 2006).

Fortunately, the study by Lee et al. (2010) offers an innovative solution to using financial data to compare the dynamic capabilities of different firms. They develop measures for the complementarity of product markets and deem those firms more dynamically capable that are able to reposition their portfolio to benefit from such complementarity as the landscape changes. Such a design takes into account environmental change and is able to measure a firm's ability to respond to such change.

Recommendation 8: Measure learning outcomes in addition to learning opportunities.

\section{Synthesis and conclusions}

Our aim in this study has been to review empirical quantitative research on dynamic capabilities in order to identify popular operationalizations of dynamic capabilities, assess how they correspond to the theoretical essence of the construct, and give recommendations for future empirical research. Our review indicates that a substantial share of empirical dynamic capabilities research is not completely in line with how the theoretical work defines the essence of dynamic capabilities.

Our findings and recommendations are summarized in Figure 1. We place the causal structure essential to dynamic capabilities theory at the center

capable in $R \& D$ than it is in marketing and $B$ is more capable in marketing than in $R \& D$. 
of the synthesis: dynamic capabilities change ordinary capabilities or the firm's broader resource base, which may eventually cause a change in firm performance. All our recommendations relate to this causal structure. First, we believe researchers should identify the ordinary capabilities that are changed by dynamic ones. Second, researchers should make sure that in their research design, dynamic capabilities have an indirect role in causing a change in performance. The third recommendation deals with common method variance: data for measuring dynamic capabilities, ordinary capabilities and performance should come from different sources. This recommendation is of special relevance to operationalizations based on managers' evaluations. If respondents are asked about both dynamic capabilities and firm performance in the same survey, they may find it difficult to draw a clear line between causes and outcomes.

Fourth, researchers should be clear on whether they see dynamic capabilities as common best practices or as unique to each firm, and operationalize them accordingly. Such a distinction would also make it possible to treat 'dynamic capabilities as best practices' and 'dynamic capabilities as firm-specific' as competing hypotheses. We believe that, in particular, studies using financial data should be careful about building continuous variables to measure the amount of dynamic capability: unique capabilities cannot logically be measured by comparing their amount between firms, and having or not having a best practice is best portrayed by a binary variable. Fifth, researchers should be consistent concerning the level of analysis throughout theory development and empirical work. If the theory operates at the organizational level, so should the data and analysis. But if the theory operates at the level of managerial decision-making, and a firm's dynamic capabilities are seen as related to managers' assessments and choices, managers' evaluations can be a relevant data source.

Our sixth recommendation relates to longitudinal data. Since dynamic capabilities theory is about change over time, longitudinal data sets may be indispensable in uncovering such processes of organizational learning and resource building. Seventh, we highlight the importance of balancing quantity, variety and fitness in measuring prior experience, actions and performance. We believe that it is essential to value experience, actions and performance, and their appropriateness, in relation to the challenges of capability development that the organization is facing. Our final recommendation points to the importance of measuring learning outcomes in addition to learning opportunities. Firms with the same learning opportunities may end up with different learning outcomes. Dynamic capabilities research could help in uncovering characteristics that contribute to such differences between firms.

We believe that the current misalignment between theory and empirical measures is a handicap for the development of the dynamic capabilities field, and also for the managers keen to implement the lessons learned in studies on dynamic capabilities. Specifically, we have shown that current empirical approaches have limitations in answering the theoretically and managerially relevant question of what types of dynamic capabilities should be built to induce a desired change. The synthesis of our recommendations can serve as a guide for dynamic capabilities researchers in building research designs, choosing operationalizations and in refining them. Therefore, our recommendations can serve as a checklist in addressing research questions with a relatively long history in dynamic capabilities literature, as well as provide guidance for developing novel research designs that address research questions so far left unanswered. We believe our recommendations will be helpful in designing empirical approaches to address research questions such as: 'What types of ordinary capabilities are most susceptible to change by dynamic capabilities?' 'What types of dynamic capabilities are the most helpful ones in changing ordinary capabilities and hence creating a change in performance?' 'Are there specific dynamic capability combinations or "profiles" that would be especially effective?' and 'How fast can dynamic capabilities create a substantial change in ordinary capabilities?' However, in addition to providing recommendations for future research, we were also able to identify several studies with exemplary applications of the dynamic capabilities construct.

So far, theory development has received plenty of attention in dynamic capabilities research, which has resulted in significant advances in conceptualizations of dynamic capabilities and their connections with other concepts. This has made it possible to identify certain widely agreed-upon principles of what constitutes dynamic capabilities and what are their key characteristics - which is what we have referred to as the essence of the construct. Hence, we believe now is an excellent opportunity for the field to direct more attention to the empirical study of dynamic capabilities. We hope that this paper will help in this by spawning new interest in further developing dynamic capabilities operationalizations and encouraging more 
reflection concerning the alignment of theoretical ideas and empirical solutions.

\section{References}

Agarwal, R. (1996). Technological activity and survival of firms. Economics Letters, 52, pp. 101-108.

Ambrosini, V. and Bowman, C. (2009). What are dynamic capabilities and are they a useful construct in strategic management? International Journal of Management Reviews, 11, pp. 29-49.

Anand, J., Oriani, R. and Vassolo, R.S. (2010). Alliance activity as a dynamic capability in the face of a discontinuous technological change. Organization Science, 21, pp. 1213-1232.

Arend, R.J. (2014). Entrepreneurship and dynamic capabilities: how firm age and size affect the 'capability enhancement-SME performance' relationship. Small Business Economics, 42, pp. 33-57.

Arend, R.J. and Bromiley, P. (2009). Assessing the dynamic capabilities view: spare change, everyone? Strategic Organization, 7, pp. 75-90.

Arthurs, J.D. and Busenitz, L.W. (2006). Dynamic capabilities and venture performance,.he effects of venture capitalists. Journal of Business Venturing, 21, pp. 195-215.

Balasubramanian, N. (2011). New plant venture performance differences among incumbent, diversifying, and entrepreneurial firms: the impact of industry learning intensity. Management Science, 57, pp. 549-565.

Barrales-Molina, V., Bustinza, O.F. and Gutierrez-Gutierrez, L.J. (2013). Explaining the causes and effects of dynamic capabilities generation: a multiple-indicator multiplecause modelling approach. British Journal of Management, 24, pp. 571-591.

Barreto, I. (2010). Dynamic capabilities: a review of past research and an agenda for the future. Journal of Management, 36, pp. 256-280.

Berg, B.L. (1995). Qualitative Research Methods for the Social Sciences. Boston, MA: allyn \& Bacon.

Bernroider, E.W.N., Wong, C.W.Y. and Lai, K.H. (2014). From dynamic capabilities to ERP enabled business improvements: the mediating effect of the implementation project. International Journal of Project Management, 32, pp. 350-362.

Bertrand, M. and Mullainathan, S. (2001). Do people mean what they say? Implications for subjective survey data. American Economic Review, 91, pp. 67-72.

Bhattacharya, M., Gibson, D.E. and Doty, D.H. (2005). The effects of flexibility in employee skills, employee behaviors, and human resource practices on firm performance. Journal of Management, 31, pp. 622-640.

Bogner, W.C. and Bansal, P. (2007). Knowledge management as the basis of sustained high performance. Journal of Management Studies, 44, pp. 165-188.

Bowman, E.H. and Hurry, D. (1993). Strategy through the option lens - an integrated view of resource investments and the incremental-choice process. Academy of Management Review, 18, pp. 760-782.

Brouthers, K.D., Brouthers, L.E. and Werner, S. (2008). Resource-based advantages in an international context. Journal of Management, 34, pp. 189-217.

Brown, S.L. and Eisenhardt, K.M. (1997). The art of continuous change: linking complexity theory and time-paced evolution in relentlessly shifting organizations. Administrative Science Quarterly, 42, pp. 1-34.

Cai, J. and Tylecote, A. (2008). Corporate governance and technological dynamism of Chinese firms in mobile telecommunications: a quantitative study. Research Policy, 37, pp. 1790-1811.

Campbell, J.P. (1982). Editorial: some remarks from the outgoing editor. Journal of Applied Psychology, 67, pp. 691700 .

Capron, L. and Mitchell, W. (2009). Selection capability: how capability gaps and internal social frictions affect internal and external strategic renewal. Organization Science, 20, pp. 294-312.

Chen, C.-W. and Lien, N.-H. (2013). Technological opportunism and firm performance: moderating contexts. Journal of Business Research, 66, pp. 2218-2225.

Cheng, C.C.J. and Chen, J.-S. (2013). Breakthrough innovation: the roles of dynamic innovation capabilities and open innovation activities. Journal of Business \& Industrial Marketing, 28, pp. 444-454.

Cook, T.D. and Campbell, D.T. (1979). QuasiExperimentation: Design \& Analysis Issues for Field Settings. Boston, MA: Houghton Mifflin.

Cowan, R. and Gunby, P. (1996). Sprayed to death: path dependence, lock-in and pest control strategies. Economic Journal, 106, pp. 521-542.

Danis, W.M., Chiaburu, D.S. and Lyles, M.A. (2010). The impact of managerial networking intensity and market-based strategies on firm growth during institutional upheaval: a study of small and medium-sized enterprises in a transition economy. Journal of International Business Studies, 41, pp. 287-307.

Danneels, E. (2008). Organizational antecedents of secondorder competences. Strategic Management Journal, 29, pp. 519-543.

David, R.J. and Han, S.K. (2004). A systematic assessment of the empirical support for transaction cost economics. Strategic Management Journal, 25, pp. 39-58.

Denrell, J., Arvidsson, N. and Zander, U. (2004). Managing knowledge in the dark: an empirical study of the reliability of capability evaluations. Management Science, 50, pp. 1491-1503.

Di Stefano, G., Peteraf, M. and Verona, G. (2010). Dynamic capabilities deconstructed: a bibliographic investigation into the origins, development, and future directions of the research domain. Industrial and Corporate Change, 19, pp. 1187-1204.

Di Stefano, G., Peteraf, M. and Verona, G. (2014). The organizational drivetrain: a road to integration of dynamic 
capabilities research. Academy of Management Perspectives, 28, pp. 307-327.

Doving, E. and Gooderham, P.N. (2008). Dynamic capabilities as antecedents of the scope of related diversification: the case of small firm accountancy practices. Strategic Management Journal, 29, pp. 841-857.

Downey, H.K., Chacko, T.I. and McElroy, J.C. (1979). Attribution of the 'causes' of performance: a constructive, quasi-longitudinal replication of the Staw (1975) study. Organizational Behavior and Human Performance, 24, pp. 287-299.

Drnevich, P.L. and Kriauciunas, A.P. (2011). Clarifying the conditions and limits of the contributions of ordinary and dynamic capabilities to relative firm performance. Strategic Management Journal, 32, pp. 254-279.

Easterby-Smith, M., Lyles, M.A. and Peteraf, M.A. (2009). Dynamic capabilities: current debates and future directions. British Journal of Management, 20, pp. S1-S8.

Eggers, J.P. (2012). All experience is not created equal: learning, adapting, and focusing in product portfolio management. Strategic Management Journal, 33, pp. 315-335.

Eggers, J.P. and Kaplan, S. (2009). Cognition and renewal: comparing CEO and organizational effects on incumbent adaptation to technical change. Organization Science, 20, pp. 461-477.

Eisenhardt, K.M. and Martin, J.A. (2000). Dynamic capabilities: what are they? Strategic Management Journal, 21, pp. 1105-1121.

Fang, E. and Zou, S. (2010). The effects of absorptive and joint learning on the instability of international joint ventures in emerging economies. Journal of International Business Studies, 41, pp. 906-924.

Felin, T., Foss, N.J., Heimeriks, K.H. and Madsen, T.L. (2012). Microfoundations of routines and capabilities: individuals, processes, and structure. Journal of Management Studies, 49, pp. 1351-1374.

Feller, J., Parhankangas, A., Smeds, R. and Jaatinen, M. (2013). How companies learn to collaborate: emergence of improved inter-organizational processes in R\&D alliances. Organization Studies, 34, pp. 313-343.

Fortune, A. and Mitchell, W. (2012). Unpacking firm exit at the firm and industry levels: the adaptation and selection of firm capabilities. Strategic Management Journal, 33, pp. 794-819.

Franco, A.M., Sarkar, M.B., Agarwal, R. and Echambadi, R. (2009). Swift and smart: the moderating effects of technological capabilities on the market pioneering-firm survival relationship. Management Science, 55, pp. 1842-1860.

Galunic, D.C. and Eisenhardt, K.M. (2001). Architectural innovation and modular corporate forms. Academy of Management Journal, 44, pp. 1229-1249.

Ganter, A. and Hecker, A. (2013). Persistence of innovation: discriminating between types of innovation and sources of state dependence. Research Policy, 42, pp. 1431-1445.

Groysberg, B. and Lee, L.E. (2008). The effect of colleague quality on top performance: the case of secu- rity analysts. Journal of Organizational Behavior, 29, pp. 1123-1144.

Groysberg, B. and Lee, L.E. (2009). Hiring stars and their colleagues: exploration and exploitation in professional service firms. Organization Science, 20, pp. 740-758.

Han, Y.Q. and Li, D.Y. (2015). Effects of intellectual capital on innovative performance: the role of knowledgebased dynamic capability. Management Decision, 53, pp. 40-56.

Heimeriks, K.H., Schijven, M. and Gates, S. (2012). Manifestations of higher-order routines: the underlying mechanisms of deliberate learning in the context of postacquisition integration. Academy of Management Journal, 55, pp. 703-726.

Helfat, C., Finkelstein, S., Mitchell, W., Peteraf, M.A., Singh, H., Teece, D.J. and Winter, S.G. (2007). Dynamic Capabilities: Understanding Strategic Change in Organizations. Oxford: Blackwell.

Helfat, C.E. (1997). Know-how and asset complementarity and dynamic capability accumulation: the case of R\&D. Strategic Management Journal, 18, pp. 339-360.

Helfat, C.E. and Winter, S.G. (2011). Untangling dynamic and operational capabilities: strategy for the (n)everchanging world. Strategic Management Journal, 32, pp. 1243-1250.

Henderson, A.D. (1999). Firm strategy and age dependence: a contingent view of the liabilities of newness, adolescence, and obsolescence. Administrative Science Quarterly, 44, pp. 281-314.

Hsu, L.-C. and Wang, C.-H. (2012). Clarifying the effect of intellectual capital on performance: the mediating role of dynamic capability. British Journal of Management, 23, pp. 179-205.

Jansen, J.J.P., Tempelaar, M.P., Van den Bosch, F.A.J. and Volberda, H.W. (2009). Structural differentiation and ambidexterity: the mediating role of integration mechanisms. Organization Science, 20, pp. 797-811.

Julian, S.D., Ofori-Dankwa, J.C. and Justis, R.T. (2008). Understanding strategic responses to interest group pressures. Strategic Management Journal, 29, pp. 963-984.

Kaplan, S. (2008). Cognition, capabilities, and incentives: assessing firm response to the fiber-optic revolution. Academy of Management Journal, 51, pp. 672-695.

Karimi, J. and Walter, Z. (2015). The role of dynamic capabilities in responding to digital disruption: a factor-based study of the newspaper industry. Journal of Management Information Systems, 32, pp. 39-81.

Karren, R.J. and Barringer, M.W. (2002). A review and analysis of the policy-capturing methodology in organizational research: guidelines for research and practice. Organizational Research Methods, 5, pp. 337361.

King, A.A. and Tucci, C.L. (2002). Incumbent entry into new market niches: the role of experience and managerial choice in the creation of dynamic capabilities. Management Science, 48, pp. 171-186. 
Kok, R.A.W. and Ligthart, P.E.M. (2014). Differentiating major and incremental new product development: the effects of functional and numerical workforce flexibility. Journal of Product Innovation Management, 31, pp. 30-42.

Kolb, D.A., Boyatzis, R.E. and Mainemelis, C. (2001). Experiential learning theory: previous research and new directions. In Sternberg, R.J. and Zhang, L.F. (eds), Perspectives on Thinking, Learning, and Cognitive Styles. Mahwah, NJ: Lawrence Erlbaum, pp. 227-248.

Kraatz, M.S. and Zajac, E.J. (2001). How organizational resources affect strategic change and performance in turbulent environments: theory and evidence. Organization Science, 12, pp. 632-657.

Kusunoki, K., Nonaka, I. and Nagata, A. (1998). Organizational capabilities in product development of Japanese firms: a conceptual framework and empirical findings. Organization Science, 9, pp. 699-718.

Kyrgidou, L.P. and Spyropoulou, S. (2013). Drivers and performance outcomes of innovativeness: an empirical study. British Journal of Management, 24, pp. 281-298.

Lampel, J. and Shamsie, J. (2003). Capabilities in motion: new organizational forms and the reshaping of the Hollywood movie industry. Journal of Management Studies, $\mathbf{4 0}$, pp. 2189-2210.

Lee, C.H., Venkatraman, N., Tanriverdi, H. and Iyer, B. (2010). Complementarity-based hypercompetition in the software industry: theory and empirical test, 1990-2002. Strategic Management Journal, 31, pp. 1431-1456.

Lee, C.Y. (2010). A theory of firm growth: learning capability, knowledge threshold, and patterns of growth. Research Policy, 39, pp. 278-289.

Lee, P.-Y., Kung, C.-Y. and Li, C.-S.J. (2015). Developing dynamic capabilities in culturally distant service multi-units. Industrial Management \& Data Systems, 115, pp. 1547-1562.

Lee, R. (2009). Social capital and business and management: setting a research agenda. International Journal of Management Reviews, 11, pp. 247-273.

Lew, Y.K., Sinkovics, R.R. and Kuivalainen, O. (2013). Upstream internationalization process: roles of social capital in creating exploratory capability and market performance. International Business Review, 22, pp. 1101-1120.

Liao, T.S. and Rice, J. (2010). Innovation investments, market engagement and financial performance: a study among Australian manufacturing SMEs. Research Policy, 39, pp. 117-125.

Lieberman, M.B. and Montgomery, D.B. (1998). First-mover (dis)advantages: retrospective and link with the resourcebased view. Strategic Management Journal, 19, pp. 11111125.

Lohrke, F.T., Holloway, B.B. and Woolley, T.W. (2010). Conjoint analysis in entrepreneurship research a review and research agenda. Organizational Research Methods, 13, pp. 16-30.

Macher, J.T. and Mowery, D.C. (2009). Measuring dynamic capabilities: practices and performance in semiconduc- tor manufacturing. British Journal of Management, 20, pp. S41-S62.

Malik, O.R. and Kotabe, M. (2009). Dynamic capabilities, government policies, and performance in firms from emerging economies: evidence from India and Pakistan. Journal of Management Studies, 46, pp. 421-450.

Marcus, A.A. and Anderson, M.H. (2006). A general dynamic capability: does it propagate business and social competencies in the retail food industry? Journal of Management Studies, 43, pp. 19-46.

Martinez-Sanchez, A., Vela-Jimenez, M.J., Perez-Perez, M. and de-Luis-Carnicer, P. (2011). The dynamics of labour flexibility: relationships between employment type and innovativeness. Journal of Management Studies, 48, pp. 715-736.

McKelvie, A. and Davidsson, P. (2009). From resource base to dynamic capabilities: an investigation of new firms. British Journal of Management, 20, pp. S63-S80.

Meyer, M.W. (2005). Can performance studies create actionable knowledge if we can't measure the performance of the firm? Journal of Management Inquiry, 14, pp. 287-291.

Moliterno, T.P. and Wiersema, M.F. (2007). Firm performance, rent appropriation, and the strategic resource divestment capability. Strategic Management Journal, 28, pp. 1065-1087.

Narasimhan, O., Rajiv, S. and Dutta, S. (2006). Absorptive capacity in high-technology markets: the competitive advantage of the haves. Marketing Science, 25, pp. 510524.

Newbert, S.L. (2007). Empirical research on the resourcebased view of the firm: an assessment and suggestions for future research. Strategic Management Journal, 28, pp. 121-146.

Pavlou, P.A. and El Sawy, O.A. (2011). Understanding the elusive black box of dynamic capabilities. Decision Sciences, 42, pp. 239-273.

Peteraf, M., Di Stefano, G. and Verona, G. (2013). The elephant in the room of dynamic capabilities: bringing two diverging conversations together. Strategic Management Journal, 34, pp. 1389-1410.

Priem, R.L. and Butler, J.E. (2001). Is the resource-based' view' a useful perspective for strategic management research? Academy of Management Review, 26, pp. 22-40.

Rosenzweig, P. (2007). The Halo Effect ... and the Eight Other Business Delusions that Deceive Managers. New York, NY: Free Press.

Rothaermel, F.T. and Hess, A.M. (2007). Building dynamic capabilities: innovation driven by individual-, firm-, and network-level effects. Organization Science, 18, pp. 898-921.

Rothaermel, F.T. and Hill, C.W.L. (2005). Technological discontinuities and complementary assets: a longitudinal study of industry and firm performance. Organization Science, 16, pp. 52-70.

Salge, T.O. and Vera, A. (2013). Small steps that matter: incremental learning, slack resources and organizational 
performance. British Journal of Management, 24, pp. 156173.

Schilke, O. and Goerzen, A. (2010). Alliance management capability: an investigation of the construct and its measurement. Journal of Management, 36, pp. 11921219 .

Shamsie, J., Martin, X. and Miller, D. (2009). In with the old, in with the new: capabilities, strategies, and performance among the Hollywood studios. Strategic Management Journal, 30, pp. 1440-1452.

Slater, S.F., Olson, E.M. and Hult, G.T.M. (2006). The moderating influence of strategic orientation on the strategy formation capability-performance relationship. Strategic Management Journal, 27, pp. 12211231.

Song, M., Droge, C., Hanvanich, S. and Calantone, R. (2005). Marketing and technology resource complementarity: an analysis of their interaction effect in two environmental contexts. Strategic Management Journal, 26, pp. 259-276.

Stadler, C., Helfat, C.E. and Verona, G. (2013). The impact of dynamic capabilities on resource access and development. Organization Science, 24, pp. 1782-1804.

Starbuck, W.H. (2005). Performance measures - Prevalent and important but methodologically challenging. Journal of Management Inquiry, 14, pp. 280-286.

Staw, B.M. (1975). Attribution of the 'causes' of performance: a general alternative interpretation of crosssectional research on organizations. Organizational Behavior and Human Performance, 13, pp. 414-432.

Strauss, A.L. (1987). Qualitative Analysis for Social Scientists. Cambridge: Cambridge University Press.

Sydow, J., Schreyogg, G. and Koch, J. (2009). Organizational path dependence: opening the black box. Academy of Management Review, 34, pp. 689-709.

Teece, D.J. (2007). Explicating dynamic capabilities: the nature and microfoundations of (sustainable) enterprise performance. Strategic Management Journal, 28, pp. 13191350.

Teece, D.J. (2012). Dynamic capabilities: routines versus entrepreneurial action. Journal of Management Studies, 39, pp. 1395-1401.

Teece, D.J., Pisano, G. and Shuen, A. (1997). Dynamic capabilities and strategic management. Strategic Management Journal, 18, pp. 509-533.

Thomas, K.W. and Tymon, W.G. (1982). Necessary properties of relevant research: lessons from recent criticisms of the organizational sciences. Academy of Management Review, 7, pp. 345-352.

Tsai, W.P., Su, K.H. and Chen, M.J. (2011). Seeing through the eyes of a rival: competitor acumen based on rivalcentric perceptions. Academy of Management Journal, 54, pp. 761-778.

Uhlenbruck, K. (2004). Developing acquired foreign subsidiaries: the experience of MNEs in transition economies. Journal of International Business Studies, 35, pp. 109123.
Wang, C.L. and Ahmed, P.K. (2007). Dynamic capabilities: a review and research agenda. International Journal of Management Reviews, 9, pp. 31-51.

Venkatraman, N. and Grant, J.H. (1986). Construct measurement in organizational strategy research: a critique and proposal. Academy of Management Review, 11, pp. 71-87.

Wilhelm, H., Schlomer, M. and Maurer, I. (2015). How dynamic capabilities affect the effectiveness and efficiency of operating routines under high and low levels of environmental dynamism. British Journal of Management, 26, pp. 327-345.

Williamson, O.E. (1999). Strategy research: governance and competence perspectives. Strategic Management Journal, 20, pp. 1087-1108.

Winter, S.G. (2003). Understanding dynamic capabilities. Strategic Management Journal, 24, pp. 991-995.

Vogel, R. and Güttel, W.H. (2013). The dynamic capability view in strategic management: a bibliometric review. International Journal of Management Reviews, 15, pp. 426-446.

von den Driesch, T., da Costa, M.E.S., Flatten, T.C. and Brettel, M. (2015). How CEO experience, personality, and network affect firms' dynamic capabilities. European Management Journal, 33, pp. 245-256.

Yaniv, E. (2011). Dialogue. Construct clarity in theories of management and organization. Academy of Management Review, 36, pp. 590-592.

Yi, Y.Q., He, X.M., Ndofor, H. and Wei, Z.L. (2015). Dynamic capabilities and the speed of strategic change: evidence from China. IEEE Transactions on Engineering Management, 62, pp. 18-28.

Zahra, S.A., Sapienza, H.J. and Davidsson, P. (2006). Entrepreneurship and dynamic capabilities: a review, model and research agenda. Journal of Management Studies, 43, pp. 917-955.

Zhou, K.Z. and Wu, F. (2010). Techological capability, strategic flexibility, and product innovation. Strategic Management Journal, 31, pp. 547-561.

Zollo, M. and Winter, S.G. (2002). Deliberate learning and the evolution of dynamic capabilities. Organization Science, 13, pp. 339-351.

\section{Supporting Information}

Additional Supporting Information may be found in the online version of this article at the publisher's website:

Table S1. The reviewed studies and categorization of the dynamic capability operationalizations presented in them

Table S2. Dynamic capability operationalized through managers' evaluations

Table S3. Dynamic capability operationalized using financial data 
Table S4. Dynamic capability operationalized as company's experience, actions and performance

Table S5. Dynamic capability operationalized using managers' or employees' experience, actions and performance
Please note: Blackwell Publishing are not responsible for the content or functionality of any supporting materials supplied by the authors. Any queries (other than missing material) should be directed to the corresponding author for the article. 